\title{
Student Dissertation Database Management System: IAMTECH Sierra Leone as a Case Study
}

\author{
Ibrahim Abdulai Sawaneh ${ }^{1, ~ *, ~ E m m a n u e l ~ C o l e ~}{ }^{1}$, Joshua Hamid Koroma ${ }^{1}$, \\ Joseph Abass Mike Kamara ${ }^{2}$, Ibrahim Sankoh ${ }^{1}$, Mohamed Sallieu Sesay ${ }^{1}$, Abu Koroma ${ }^{1}$ \\ ${ }^{1}$ Department of Computer Science, Institute of Advanced Management and Technology (IAMTECH), Freetown, Sierra Leone \\ ${ }^{2}$ Department of Software Engineering, Nankai University, Tianjin, China
}

Email address:

ciddiisawaneh@hotmail.com (I. A. Sawaneh)

${ }^{*}$ Corresponding author

\section{To cite this article:}

Ibrahim Abdulai Sawaneh, Emmanuel Cole, Joshua Hamid Koroma, Joseph Abass Mike Kamara, Ibrahim Sankoh, Mohamed Sallieu Sesay, Abu Koroma. Student Dissertation Database Management System: IAMTECH Sierra Leone as a Case Study. International Journal on Data Science and Technology. Vol. 4, No. 3, 2018, pp. 93-99. doi: 10.11648/j.ijdst.20180403.13

Received: September 9, 2018; Accepted: September 25, 2018; Published: October 25, 2018

\begin{abstract}
As a big data technological innovation emerges due to man's continuous use of data, it has prompted an immediate attention that will provide necessary solutions to cope with the current trend of data usability. Universities and colleges process large datasets in trillions of bytes to the extent that the traditional filling system can no longer handle them. Having thousands of students' dissertations to process will be huge problem using the traditional filling system that requires large physical storage space with lots of inconsistencies, when it comes to processing, analyzing and archiving records is a big challenge, especially checking for plagiarism. Therefore, this research is designed to eliminate the challenges posed by the traditional platform that incurs huge amount of money and time. The proposed scheme is known as "IAMTECH Dissertation Database Management Platform" which is currently in use at the testing stage as an effective solution for proper record keeping and retrieval with minimal cost. The system has proved effective and efficient as compared to the old system. New functionalities are required to be included in the new system in the near future as the need arises due to intensive advancement in the information and data usage.
\end{abstract}

Keywords: IAMTECH, Database Management Platform, Big Data

\section{Introduction}

The idea of using database platform began about five and half decades ago when most industrialized nations around the world archived their data in a database management system. This scheme provided organizations and institutions with numerous benefits that are cost-effective and efficient. Database management system is a coherent collection of data with an inheritance meaning representing the real world. It creates, maintains, manipulates, edits, retrieves, backups, and stores datasets. Database is an important asset to any institution as it helps the effective day-to-day operations with ease and efficiency. It summarizes the overall activities and helps managers to make effective managerial decisions that produce optimal results. It is used in educational informatization that mitigates most of the challenges faced by the out-fashioned database systems. This is important with the notion that higher educational institutions should be able to provide solutions to societal problems, database management system, being the perfect alternative to solve issues with storage, and data manipulation. It assures data accuracy, consistency, efficiency and minimal cost. The principal aim of the research is to design student information system that will enable strategic management in an educational institution to monitor and make accurate decision especially at the Institution of Advanced Management and technology (IAMTECH) Sierra Leone.

\subsection{Research Objective}

The principal objective is to design an effective database management platform that can handle students' dissertations at IAMTECH. 


\subsubsection{Specific Objectives}

1. To design a database management platform that houses IAMTECH dissertations;

2. To allow the administration to verify topics as a way to stop repetition of topics by students;

3. To enhance the administration to effectively collect data, analyze, compute, store, generate forms, and a print function;

4. To identify future issues associated with managing students' dissertations;

5. To design a proposed database platform with an integrated multiple purposes used at IAMTECH.

\subsubsection{Research Rationale}

Achieving proper archaic system in any educational institution is vital for future retrieval. Therefore, the research utilizes IAMTECH students' dissertation platform for efficiency and effectiveness.

\subsection{Motivation}

This research was carried out taking into consideration of large data consumptions globally with reference to big data platform. The traditional filling system has become out-dated and can no longer handle the massive flow of data in an institution. Therefore, the proposed scheme will effectively collect students' dissertations, analyze, process, store and print the results in accordance with the IAMTECH dissertation guidelines, including uniformity. It enhances an effective platform that can keep track of all dissertations written by IAMTECH students.

\subsubsection{Scope}

The proposed system is designed to basically solve the inconsistency associated with the traditional method of processing students' dissertation at IAMTECH. It constitutes as part of the student management information system. It has been tested and proven effective, solving about $85 \%$ of the problem associated with the flaws of the old system. The scheme has features such as names of students, ID, departments, topics, case studies if required, grades, name of supervisors, print functions, and search bar to search for duplication or repetition of topics.

\subsubsection{Research Question}

Was there any students' dissertation at IAMTECH in the past?

No, it was done manually and stored in hard copies since the institution was created. Therefore, a proposed new students' dissertation database management system is designed to be used along with the existing platform, which has proven efficient and effective.

\section{Related Works}

Extensive research was done in producing this document. The concepts underlying our work can be referenced to Abraham Silberschatz (2002) in their book titled database system concepts, indicating the superiority of database system as compared to file system. In their analysis, they indicated how the file processing systems are supported by conventional platform. The platform records information permanently in various files and different application programs. It constitutes part and parcel of the challenges students' management system faces.

A file system is seeing an outdated information processing system with the following demerits:

1. Data redundancy and discrepancy

2. Ineffective data access

3. Data isolation issues

4. Integrity issues

5. Atomicity issues

6. Concurrent access anomaly issues

7. Security issues

These complications among others necessitate the advert of database management systems as stated by Jeffrey A. Hoffer et al (2002) arguing that, there are impurities in the file processing systems in a book titled "Modern Database Management". They exposed the numerous merits that are associated with database management system including:

1. Program - data autonomy

2. Negligible data redundancy

3. Enhanced data reliability

4. Enhanced data sharing

5. Utilization of applicable standards

6. Enhanced data accessibility and responsiveness.

7. Reduce programs maintenance.

Abraham Silberschatz et al (2002), viewed database system as a collection of interrelated files and set of program that permitted user to access and modify these files. Database renders users abstract views of the data, i.e., hiding certain features and presenting a user-friendly interface to the users. Jeffrey A. Hoffer et al (2002) talked about the various types of database applications from a single client to multiple clients.

\subsection{Database as a Tool for Efficiently Record Students' Data}

Database is referred to a collective set of logically interrelated data designed with the view to meet numerous information consumptions. It houses thousands of information with minimal duplication to form an integrated record that solves the information needs of an organization Greenwald et al., 2005; Connolly and Begg, 2004).

Database management system is an effective computational information management tool that processes data with the aim to store data in a readily available for easy retrieval, manipulation, and production of information. Just like the laws of Newton, it exhibits both pros and cons as highlighted below:

\subsection{Advantages of Student Database Management System}

Improved data sharing: It provides an ecosystem with 
improved sharing of vital information. With its user friendly interface, one can easily give command and immediately the system will respond in few seconds making it overcome time wastage seen in the file management system.

Enhanced data security: It provides better security and privacy platforms as opposed to the traditional file system. When sensitive documents are accessible to everybody in an organization raises a high security risk. Passwords and other security features are usually used in a database management system in order to allow authorized user access.

Increased data integration: It's a constitutes all the data collected from the all departments within an organization from which top management makes decisions based on the organization's blueprint. It is easier to monitor all the activities of the organization in one platform rather than separately.

Mitigate data inconsistency: It is easy to eliminate or mitigate data repetition/inconsistency, as each entry in the database is unique from the other.

\subsection{Advantages of Student Database Management System}

High costs: The minimal cost in renewing licenses, regulation costs, and training of staff regularly high due to the improved hardware infrastructure.

Complexity: Most database management systems are regularly updated with new features added thereby creating more complexity in the software usage that may have an adverse effect on the organization's resources and culture. This should ensure that the objective of the organization is not misplaced.

Regular upgrading: Software developers continuously upgrade by adding features to their product that are tied to additional spending (upgrading fees, more training, etc.).

\section{Methodology}

This project is designed using a structure system analysis and design methodology (SSAM). It is based on the principle of structure analysis relatively than the data subjects for processing.

\subsection{Operational Mode}

The administration collects the student details including the draft copy of the dissertations from the students, performs plagiarism check, if the work is not up to expectation returns it to the student for improvement, when the required modification is done. The students take it to the printing department for formatting and printing. Students then take the formatted work to the database administrator to upload into the database management system.

\subsection{Database Management System (DBMS)}

A database management system (DBMS) is a computergenerated paradigm that is geared towards managing database system. It is an integrated software platform that renders several functions for the effective administration of information management system. It is predesigned software that collects, analyzes, stores, updates and retrieves database according to Gerald C. Okereke, (2009).

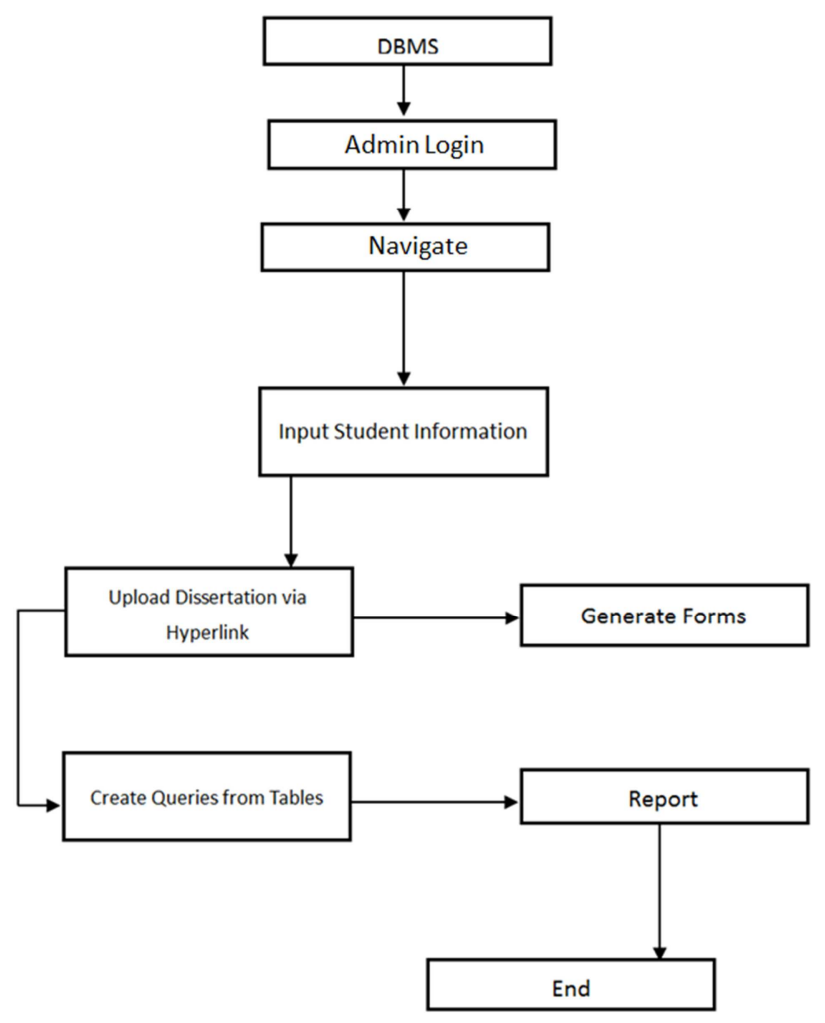

Figure 1. System Architecture Design.

\begin{tabular}{l}
\multicolumn{1}{c|}{ Requirements Analysis of the Proposed System } \\
\hline Student ID \\
Level \\
Academic Year \\
Campus \\
First Name \\
Last Name \\
Department \\
Topic \\
Case Study \\
Supervisor \\
Dissertation Upload
\end{tabular}

Figure 2. Requirements of the Proposed System. 


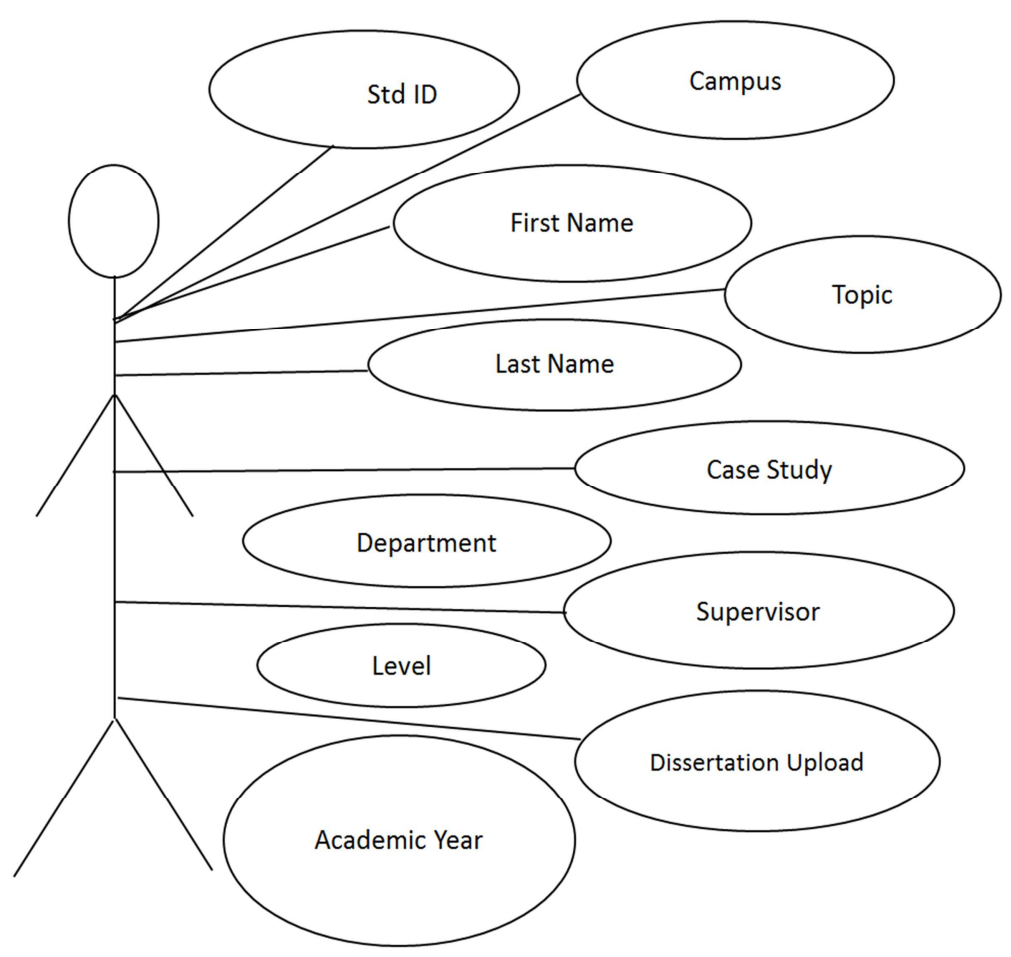

Figure 3. Entity Relation Diagram.

\section{Development}

You start by initialize Microsoft Access 2007, 10, 13. Then on the design view you develop your database scheme. However after developing the scheme using selected fields and appropriate data types, you move to the datasheet view and enter record into the table. The table holds records for future references and outputs. It is important to note that records on a table could be monitored, modified and deleted if necessary.

\subsection{System Requirements}

This is divided into two parts:

\subsection{Hardware Requirements}

1. Pentium IV Processor

2. $8 \mathrm{~GB}$ of Ram

3. 100 GB Hard Drive

\subsection{Software Requirements}

1. Operating System: Windows 7, 8 \& 10

2. Database: Microsoft Access

\section{Results}

The evaluated package will be developed using Microsoft Access. Several screenshots is shown to indicate how it operates. The results indicate that the researchers attain their goals by providing a complete system that records, analyze, modifies, backups, stores, retrieves and prints the processed data for managerial decisions. It is also cost-effective with easy user interface that motivates users, Greenwald et al., 2005; Connolly and Begg, 2004).

\section{Discussion}

\subsection{Principal's View on the Proposed System}

IAMTECH being a technology institution in Sierra Leone is seen to be moving towards cloud computing. This is a positive sign in the current informatization. Having a Student Dissertation Database Management System helps minimize constraints faced by the old system.

\subsection{Dissertation Committee's View on the Proposed System}

It is a positive achievement, as now students' dissertations will be kept in an archive system for a long period of time in large volume. It is now possible to detect duplication of topics done within the last four years, adhering to the institution's formatting style, plagiarism check, and other parameters approved by the institution. The system requires more improvement by adding a scripting domain such as MySQL, allowing a possible web adaptation.

\section{Conclusion}

The proposed scheme developed is a student information system that enhances institutions to effectively manage their information systems. It meets IAMTECH expectations because of the easy and comfortability use. It provides an automated and enhanced database that manages the proper recording of students' dissertations, and also checks for the comparison. Managers at the end of the fiscal year easily 
make the best decision with several performance levels using the proposed system.

\section{Recommendations}

With the impact of big data innovation, it has increased the usage of trillions of data. To effectively manage and maintain the required standards relating to recording student details require a broader scope. The authors recommend an enhanced and robust software application to be used in developing a more sophisticated database application with web domain. A guidance detail should be included into the database for proper monitoring the activities of students. Furthermore, student performance criteria should also be included such as test scores, exam grades, GPA and others thereby enhancing the functionality model of the system. Moving towards the cloud is a preferred solution to the effective implementation of student dissertation database management system via a web base platform.

\section{Acknowledgements}

The authors would like to thanks Professor Paul Kamara, wife Dr. (Mrs.) Abie Paula Kamara, Dr. Michael N. Wundah, Prof. Prince Sorie Conteh, and Mrs. Elizabeth GumaSawaneh, all of the Institute of Advanced Management and
Technology (IAMTECH) for their support and encouragement.

\section{Appendix}
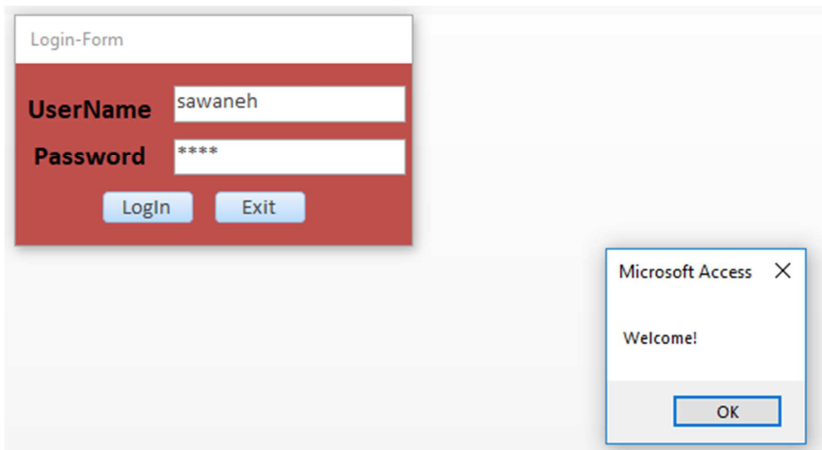

Figure A1. Unser Login Page

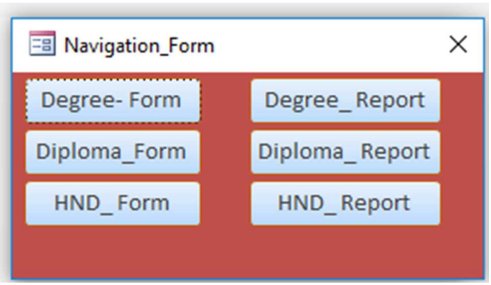

Figure A2. User Interface.

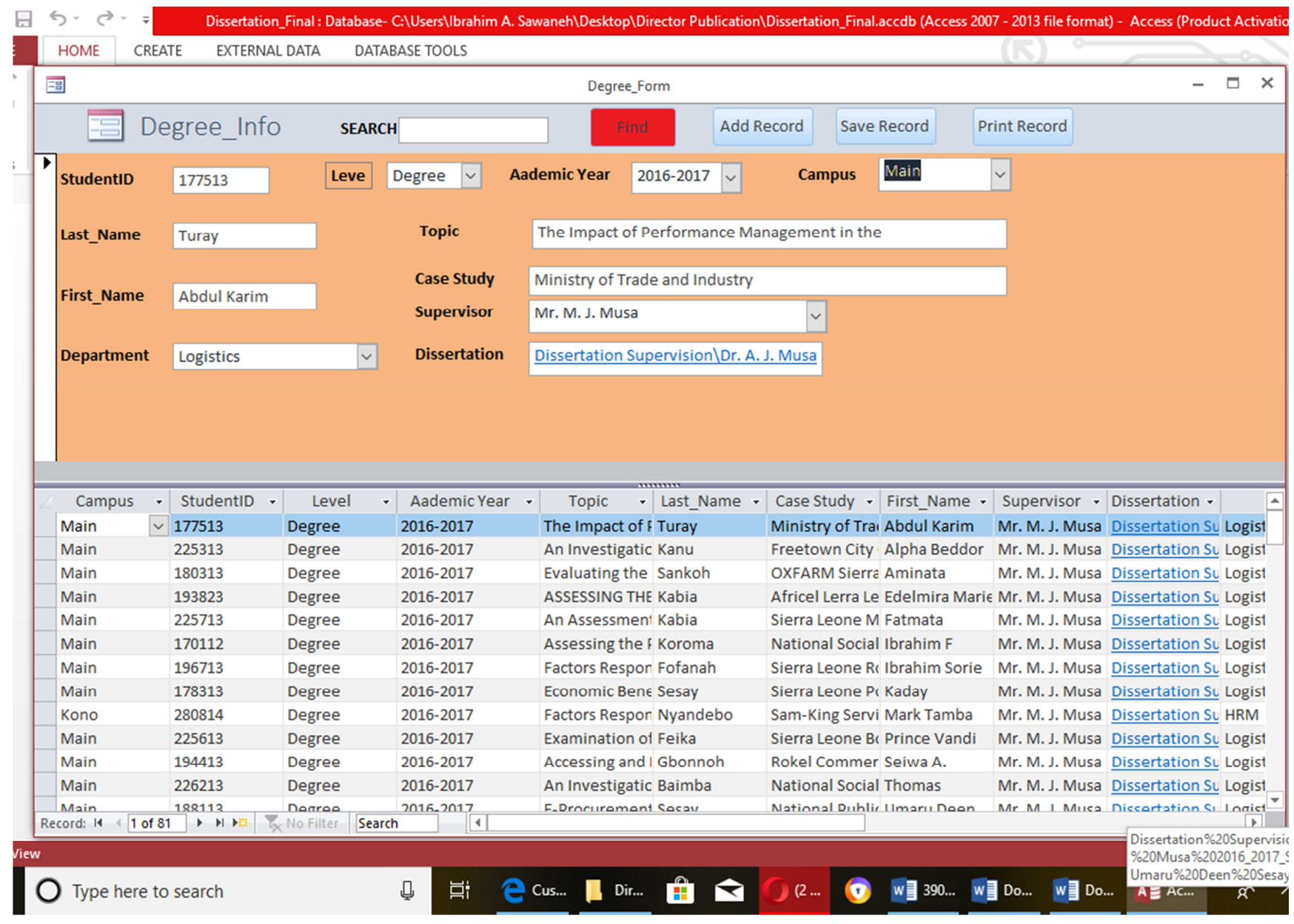

Figure A3. Degree Form. 


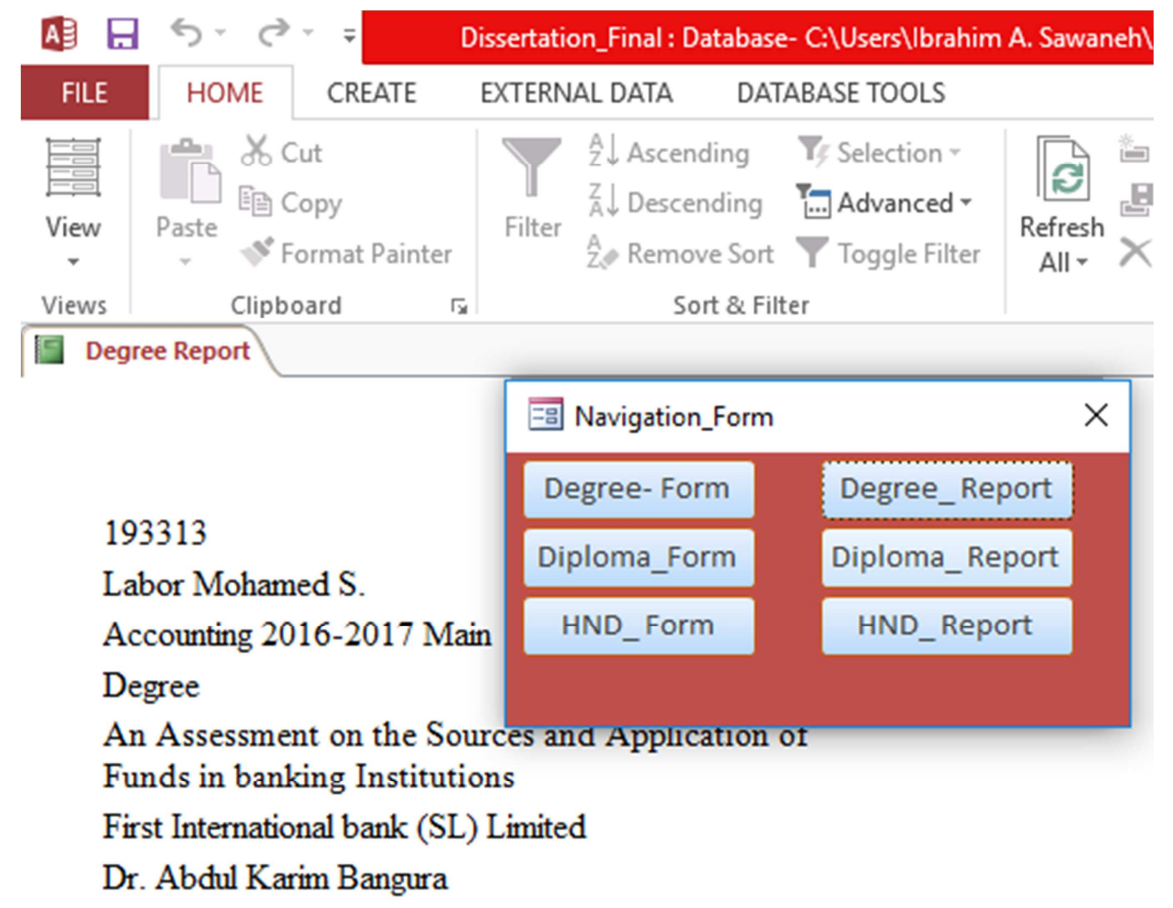

170613

Turay Abu Bakarr

Accounting 2016-2017 Main

Degree

An Analysis of the Financial Control Measures

Adopted by a Parastatal

Sierratel

Dr. Abdul Karim Bangura

203913

Sanu Adjiatu

Accounting 2016-2017 Main

\begin{tabular}{|c|c|c|}
\hline Form View & & \\
\hline Type here to search & 亘i & C Cus... \\
\hline
\end{tabular}

Figure A4. Report.

\section{References}

[1] Abraham Silberschatz, Henry F. Korth, S. Sudarshan. Database System Concepts. 2001, 4th Edn.

[2] Jeffrey A. Hoffer, Mary B. Prescott, Fred R. McFadden, 2002. Modern Database Management. 6th Edn.

[3] http://www.webopedia.com. (Data Download Date: 3 Nisan 2018).

[4] Shimozono K., Itsukiy M., Harasaka Y. and Furukawa Z., (2010), "User Management in an Educational Computer System: Personal Information Management," Fukuoka, Japan, pp. 1-6.
[5] Connolly, T. M. and C. E. Begg, 2004. Database System: A Practical Approach to Design, Implementation and Management. 4rd Edn., Addison Wesley; ISBN: 10: 0321210255 , pp: 1236.

[6] Adams, C., Beath, C. M, Bolan, R., Branin, J., D’Elia, G., Rhode, N. L. \& Straub, D. 1991. Issues Relating to the Implementation and Management of an Integrated Information Centre. Journal of the American Society for Information Science.

[7] Adman, P. \& Warren, L. 1996. Information systems management: Perspectives for Higher Education. Lancs: Mir Press.

[8] Angell, I. O. \& Smithson, S. 1991. Information Systems management: Opportunities and Risks. London: Macmillan Education Ltd. 
[9] Association for the Development of Education in African. 2001. Technology as a Management Tool: A New Approach and Implementation. http//www.technologia.org/ [accessed on 23rd May 2011].

[10] Greenwald, R., R. Stackowiak, G. Dodge, D. Klein, B. Shapiro and C. G. Ghelliah, 2005. Professional Oracle Programming. Wrox, ISBN: 10: 0764574825, pp: 790.

[11] Blaha M Rumbaugh 2005 (2nd ed.) Object-Oriented Modeling and Design with UML. [Basically this is the second edition of Rumbaugh et al 1991]. Prentice Hall.

[12] Fry B. G. 1997. The Family Educational Rights and Privacy Act of 1974. In Student Records Management, edited by M Theresa Ruzicka and Beth Lee WeckMulle. London: Greenwood Press, 43-76.

[13] Higgins, J. C. 1976. Information Systems for Planning and Control: Concepts and Cases. London: Edward Arnold.

[14] Husain, K. M. 1977. Information Systems: Basic Concepts, Management Information Systems for Higher Education.
Paris: The Organization for Economic Co-operation and Development.

[15] Gerald, C. O. 2009. Database Management System. Nigeria National Open University.

[16] Kroenke, D. \& Hatach, R. 1994. Management Information Systems, 3rd edition. New York: McGraw-Hill.

[17] Tate, M., Evermann, J., Hope, B. \& Barnes, S. 2009. Stakeholder Expectations of Service Quality in a University Web Portal. Self-Service in the Internet Age, 1-21.

[18] Telang, R. \&Mukhopadhyay, T. 2005. Drivers of Web portal use. Electronic Commerce research and applications, 4, 4965 .

[19] Maedche, A., Motik, B., Stojanovic, L., Studer, R. \&Volz, R. 2003. Ontologies for enterprise knowledge management. IEEE Intelligent Systems, 26-33. 